\title{
A new way to measure milk yield persistency: a genetic point of view with application to Gyr (Bos indicus) cattle
}

\author{
Rodrigo Junqueira Pereira ${ }^{1,2 *}$, Denise Rocha Ayres ${ }^{1,2}$, Lenira El Faro ${ }^{3}$, Aníbal Eugênio Vercesi Filho ${ }^{3}$, \\ Rui da Silva Verneque ${ }^{4}$ and Lucia Galvão de Albuquerque ${ }^{1}$ \\ 'Departamento de Zootecnia, Faculdade de Ciências Agrárias e Veterinárias, Universidade Estadual Paulista, Rodovia Carlos Tonnani, \\ Km 5, CEP 14870 -000 Jaboticabal, SP, Brazil \\ ${ }^{2}$ Grupo de Melhoramento Animal de Mato Grosso (GMAT), Instituto de Ciências Agrárias e Tecnológicas, Universidade Federal de Mato \\ Grosso, MT-270, Km 06, CEP 78735-001, Campus Rondonópolis, MT, Brazil \\ ${ }^{3}$ Instituto de Zootecnia, Rodovia Carlos Tonanni, Km 94, CEP 14160-900, Sertãozinho, SP, Brazil \\ ${ }^{4}$ Embrapa Gado de Leite, Rua Eugênio do Nascimento, 610, Bairro Dom Bosco, CEP 36038-330, Juiz de Fora, MG, Brazil
}

Received 23 March 2015; accepted for publication 11 June 2015; first published online 5 August 2015

\begin{abstract}
The objective of this work was to estimate genetic parameters for a measure of persistency of milk yield and to evaluate its association with 305-d cumulative milk yield and lactation length. 12346 records from 8202 dairy Gyr cows including lactations up to fifth calving were used. The measure of persistency was obtained from one of the parameters of a quadratic model that describes the cumulative yield across lactation as a function of days in milk. A three-trait multivariate analysis was done. Heritability and repeatability for persistency were 0.08 and $0 \cdot 21$, respectively. Deviance Information Criterion provided evidence that the additive genetic covariance between the measure of persistency studied and 305-d cumulative yield is zero. Genetic correlations between persistency and lactation length were 0.50 and $0 \cdot 27$ for first or all lactations, respectively. Milk yield persistency as measured in this study has low heritability. Selection for persistency can increase lactation length. The measure of milk yield persistency studied here is genetically independent of total milk yield and can be included in routine genetic evaluations of dairy cattle.
\end{abstract}

Keywords: Bayesian inference, dairy cattle, genetic parameters, persistency.

The predominant milk production system in tropical regions is based on pastures, meaning that the dairy Zebu breeds and their crosses are the main genetic option for these systems. One peculiarity of pasture-based milk production systems is the nutritional limitation to maximum milk yield of the animals. According to Santos et al. (2007), the maximum yield is approximately $14 \mathrm{~kg}$ milk/d for cows exclusively fed tropical forages and $30 \mathrm{~kg}$ milk/d for cows receiving concentrate feeds as supplement on intensively managed tropical pastures. Therefore, one important factor that needs to be improved simultaneously with total milk yield in dairy cattle breeding programs that address milk production on tropical pastures is persistency of milk yield, since this would permit one to increase milk production by genetically modifying the shape of the lactation curve. As a consequence, more persistent cows would produce larger amounts of milk during lactation without

*For correspondence; e-mail: rodjunper@gmail.com the need to increase peak yield, which is limited in pasture-based production systems.

Although selection for higher milk yield simultaneously promotes an increase of food intake by the animals, medium-high production cows at the beginning of lactation are unable to consume sufficient feed to meet their nutritional requirements, a fact resulting in a negative energy balance and the mobilisation of body reserves. These factors may compromise reproductive activity and increase the susceptibility to metabolic diseases (Butler, 2000). As a consequence, cows with lower production at the beginning of lactation and higher persistency will be subject to less physiological stress, thus minimising the incidence of reproductive problems and metabolic disorders (Togashi \& Lin, 2004).

Studies have reported favourable genetic associations of persistency with some reproductive traits and disease susceptibility and unfavourable associations with other traits like calving interval (Jakobsen et al. 2003; Muir et al. 2004; Harder et al. 2006). Appuhamy et al. (2007, 2009), studying associations between the incidence of 
diseases and a measure of persistency that is independent of total milk yield, concluded that persistency appears to be affected by the incidence of diseases and not viceversa.

The most recent definition of persistency are based on predicted breeding values for yield as a function of days in milk obtained with random regression models (Jakobsen et al. 2002; Pereira et al. 2012). However, most of these measures show medium to high genetic correlations with milk yield. According to Cole \& Null (2009), selection based on a measure of persistency that shows a high and positive genetic correlation with milk yield is contradictory because of the negative association between disease resistance and milk yield. Therefore, measures of milk yield persistency that are independent of total milk yield and that are easily obtained and interpreted, as proposed by Cole \& Vanraden (2006), are desired.

Given the occurrence of short lactations (less than $200 \mathrm{~d}$ ), a genetic peculiarity of the dairy Zebu breeds (Pereira et al. 2013), breeders use lactation length as a measure of persistency. However, the measures of milk yield persistency proposed around the world are related to shape of lactation.

Kamidi (2005) proposed a measure of milk yield persistency obtained from a simple quadratic model that was used to fit cumulative yield across lactation. According to the author, this measure is phenotypically independent to total yield. However, we found no genetic association studies using this measure of persistency. Therefore, the objective of the present investigation was to estimate genetic parameters for a measure of milk yield persistency (Kamidi, 2005) to better understand it under the genetic point of view, and to evaluate its associations with 305-d cumulative yield and lactation length of dairy Gyr cattle.

\section{Materials and methods}

The data used in this study were obtained from the Official Dairy Control Service of Gyr cattle, which are stored in the Brazilian National Dairy Cattle Archive (Arquivo Zootécnico Nacional) managed by National Center for Dairy Cattle Research (Embrapa Gado de Leite) - Brazil. A total of 157933 test-day milk yield records from 8202 dairy Gyr cows, recorded between 1988 and 2010, were used. The following criteria were established for inclusion of the information in the data set: age at calving ranging from 22 to 150 months; first test performed within $45 \mathrm{~d}$ after calving; intervals between test days less than $45 \mathrm{~d}$; a minimum of four test-day records per lactation; only complete (finished) lactations. Records of cows with 305-d cumulative milk yields or a lactation length outside the mean \pm 3 standard deviations were eliminated from the study. The months of calving were divided into four seasons: rainy season (December, January and February); transition between rainy and dry season (March to May); dry season (June to August), and transition between dry and rainy season (September to November).
The following traits were studied: persistency of milk yield until $305 \mathrm{~d}(\mathrm{P})$, lactation length (LL), and 305-d cumulative milk yield (Y305).

Cumulative milk yield across lactation can be represented graphically by a curve that resembles the initial path of a projectile under gravity. On the basis of this analogy, Kamidi (2005) proposed a measure of milk yield persistency obtained from a simple quadratic model as follows: $y=\beta t+$ $\gamma t^{2}+\varepsilon$ (Model 1), where y is cumulative milk yield until day $t$ of lactation, $\beta$ and $\gamma$ are constants, and $\varepsilon$ is a random error associated with the model. $\beta$ is a parameter that corresponds to the estimated peak milk yield and is highly associated with complete lactation cumulative yield. The deceleration constant $\gamma$ is associated with the decline in milk yield after peak lactation. Deceleration in yield across lactation is the value of the second derivative (Kamidi, 2005):

$\mathrm{d}^{2} y / \mathrm{d} t^{2}=2 \gamma$

In theory, if the deceleration constant $\gamma=0$, there is no decline in daily milk yield across lactation and the cumulative yield curve becomes a line. However, during normal lactation the milk yield is expected to decrease after peak lactation and $\gamma$ will thus be negative. Persistency of milk yield is inversely proportional to yield deceleration and the minimum decline or maximum persistency will occur when $\gamma=0$ (Kamidi, 2005). Therefore, a per cent measure of milk yield persistency can be obtained by $P=100(1+2 \gamma)$ (Kamidi, 2005).

Cumulative test-day milk yields are characterised as time series data, i.e., observations (phenotypic records) obtained sequentially over time (lactation). Since the assumption of independence between residuals is frequently not true for this type of data set, the Durbin-Watson test was used to identify first-order residual autocorrelation, adopting a level of significance of $1 \%$. Thus, a first-order autoregressive model was used to obtain individual deceleration constants $(\gamma)$. The general model can be described as:

$y_{i j}=\beta_{i} t+\gamma_{i} t^{2}+\varphi \varepsilon_{i j-1}+\varepsilon_{i j}$

where $y_{i j}$ is the $j$ th observation of cumulative milk yield until day $t$ of lactation of cow $i ; \beta_{i}$ and $\gamma_{i}$ are parameters of the cumulative yield curve of cow $i ; \varphi$ is the first-order autoregression coefficient; $\varepsilon_{i j-1}$ is an error associated with observation $j-1$ of cow $i$, and $\varepsilon$ is a random error associated with observation $j$. On the basis of parameter $\gamma_{i}$, individual persistency $\left(\mathrm{P}_{i}\right)$ was calculated as follows:

$P_{i}=100\left(1+2 \gamma_{i}\right)$

After the confirmation of data consistency and calculation of the measure of persistency, 12346 records from 8202 cows, daughters of 802 sires, were used. The cows belonged to 220 herds located mainly in the southeastern region of Brazil, but also in the northeast, centre-west and south of the country. The pedigree was traced back 5 generations, resulting in a pedigree file containing 16892 animals.

To know the average daily milk yield curves of cows with different levels of persistency, lactation curves were 
obtained by fitting test-day yields of the cows that participated in the study using a logarithmic Ali and Schaeffer function (Ali \& Schaeffer, 1987).

Two analyses were performed, one including only first lactations (AN1) and the other including lactations up to fifth calving (AN5). A three-trait multivariate model was used for analysis of the traits, which can be described in matrix form as follows: $Y=X b+Z a+W p+e$, where $y$ is the vector of observations; $b$ is the vector of systematic effects (contemporary group defined by herd-year-season of calving and linear and quadratic effects of age of cow at calving); $a$ is the vector of random additive genetic effects; $p$ is the vector of random effects of the permanent environment; $e$ is the vector of the random residual effect, and $X, Z$ and $W$ are incidence matrices corresponding to the observations for systematic, random additive genetic and permanent environmental effects. The following assumptions were made for this model:

$$
\begin{aligned}
& y \mid b, a, p, R \sim \operatorname{NMV}(X b+Z a+W p, R), \\
& \operatorname{Var}\left[\begin{array}{l}
a \\
p \\
e
\end{array}\right]=\left[\begin{array}{ccc}
\Lambda_{\mathrm{A}} \otimes A & 0 & 0 \\
0 & \Lambda_{\mathrm{P}} \otimes I & 0 \\
0 & 0 & R \otimes I
\end{array}\right]
\end{aligned}
$$

where $\Lambda_{\mathrm{A}}, \Lambda_{\mathrm{P}}$ and $R$ are, respectively, the additive genetic, permanent environmental and residual covariance matrices for the traits; $A$ is the numerator relationship matrix; $I$ is an identity matrix, and $\otimes$ is the direct product between matrices. For analysis of AN1, vector $\mathrm{p}$ and its corresponding matrix $W$ were excluded from the model. The prior distributions assumed for the parameters of the model were:

$$
\begin{aligned}
& b \propto \text { constante, } \\
& a \mid \Lambda_{\mathrm{A}} \sim \operatorname{NMV}\left(0, \Lambda_{\mathrm{A}} \otimes A\right), \\
& p \mid \Lambda_{\mathrm{P}} \sim \operatorname{NMV}\left(0, \Lambda_{\mathrm{P}} \otimes I\right), \\
& \Lambda_{\mathrm{A}} \mid v_{a}, S^{2}{ }_{a} \sim \mathrm{WI}\left(v_{a}, v_{a} S^{2}{ }_{a}\right), \\
& \Lambda_{\mathrm{P}} \mid v_{p}, S^{2}{ }_{p} \sim \mathrm{WI}\left(v_{p}, v_{p} S^{2}{ }_{p}\right), \\
& R \mid v_{e}, S^{2}{ }_{e} \sim \mathrm{WI}\left(v_{e}, v_{e} S^{2}{ }_{e}\right),
\end{aligned}
$$

where NMV and $\mathrm{WI}$ indicate multivariate normal and inverted Wishart distributions, respectively, and $v_{a} S_{a}^{2}, v_{p}$, $S_{p}^{2}$ and $v_{e}, S_{e}^{2}$ correspond to the confidence level and prior values for additive genetic, permanent environmental and residual covariances, respectively.

Inferences on the parameters of interest were made based on their corresponding marginal posterior distributions using Gibbs sampling. For each analysis, two chains of 1000000 samples each were generated. Using a burnin period of 50000 samples and thinning interval of 50, inferences were made on the remaining 19000 samples. The GIBBS2F90 program (Misztal, 2011) was used for analysis and convergence was monitored using the boa package of the R software (Smith, 2007).

In addition, two-trait analysis (Y305 and $P$ ) was performed to obtain statistical evidence of the genetic association between these two traits. The deviance information criterion
(DIC) (Spiegelhalter et al. 2002) was calculated for the model including additive genetic covariance $\left(\mathrm{COV}_{\text {add }}\right)$ between traits (MCOV1) and for the model without this component $\left(\mathrm{COV}_{\text {add }}\right.$ fixed at zero) (MCOV0). Thus, the DIC for each model was obtained by:

$\mathrm{DIC}=\bar{D}(\theta)+p_{\mathrm{D}}=2 \bar{D}(\theta)-D(\bar{\theta})$

where $\bar{D}(\theta)=E_{\theta \mid y}[D(\theta)]$ is the posterior expectation of Bayesian deviance and $D(\theta)=-2 \log p(y \mid \theta)$ indicating the goodness-of-fit of the model. The effective number of parameters represents a penalty for increasing model complexity: $p_{D}=\bar{D}(\theta)-D(\bar{\theta})$, where $\theta$ is the vector of model parameters and $D(\bar{\theta})$ is the Bayesian deviance evaluated at the posterior mean of the parameters. The model providing the lowest DIC value is the most adequate. A difference in DIC values higher than 7 units was considered to be important (Spiegelhalter et al. 2002).

The genetic trend in $P$ was estimated by linear regression of predicted breeding values of the animals (sires and cows) on their years of birth considering the period from 1985 to 2006.

\section{Results and discussion}

The mean coefficient of determination $\left(R^{2}\right)$ was 0.9995 (minimum of 0.9886), when the individual curves of cumulative milk yield were fitted with the quadratic model (Model 1). This coefficient can be used as a measure of the goodness-of-fit of the regression model and indicates that the model was adequate to fit cumulative milk yield across lactation. Higher estimates of $P$ were observed for first-lactation cows (Table 1). According to Lang et al. (2012), one possible explanation is the low level of mammary gland development of primiparous cows, limiting the maximum expression of peak yield. Considering all lactations up to fifth calving (AN5) (Table 1), the average $P$ was similar to that reported by Kamidi (2005) who used data from a herd of Holstein-Friesian and Ayrshire cattle in Kenya. Lower values have been reported by Hickson et al. (2006) for four herds of Holstein-Friesian and Jersey cattle in New Zealand. The coefficient of variation for $P$ in the first lactation and lactation up to fifth calving is small, indicating that the phenotypic variability in this trait is of low magnitude in the Gyr breed. However, this small variability had a marked impact when a more detailed analysis was performed (Figs. 1, 2).

Curves for cumulative milk yield across lactation obtained for cows that presented the same peak yield $(14 \mathrm{~kg}$, average peak for this population) and different levels of $P$ illustrate the impact of variation in $P$ on Y 305 and LL in cows with the same peak yield (Fig. 1). A gradual decline in Y305 (mean of $13.65 \%$ ) was observed per one per cent reduction in $P$. When $P$ declined from 94 to $90 \%$, LL decreased by $28 \mathrm{~d}$ per one per cent reduction in $P$.

Distinct patterns of the lactation curve were observed for cows with different levels of $P$ (Fig. 2). Cows with high 
Table 1. Number of observations ( $n)$, means, standard deviations and coefficients of variation (CV) obtained for the traits studied

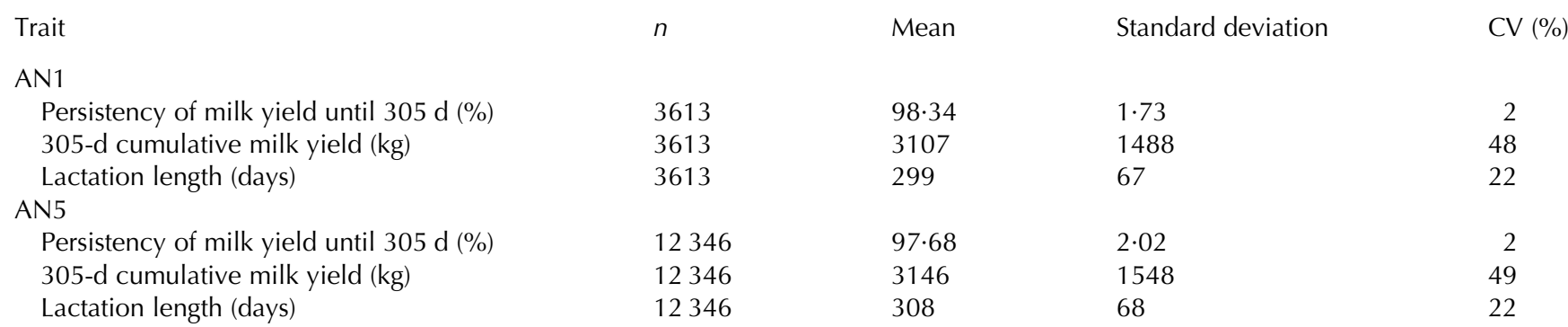

AN1, analysis considering only first-lactation cows; AN5, analysis considering all lactations up to fifth calving.

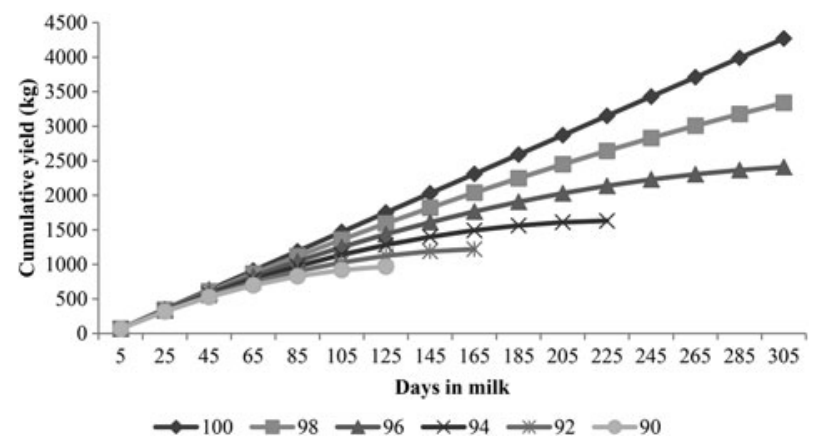

Fig. 1. Simulated curves for cumulative milk yield across lactation obtained for cows with the same peak yield $(14 \mathrm{~kg})$ and different levels of milk yield persistency until 305 d (90-100\%).

$P$ presented flat lactation curves characterised by constant daily yields across lactation and the absence of lactation peaks. In contrast, the lactation curves of cows with lower levels of $P$ were characterised by high peaks and marked declines in daily yields after peak lactation (Fig. 2). Average LL also differed depending on the level of $P$, ranging from $281 \mathrm{~d}(P=95 \%)$ to $308 \mathrm{~d}$ ( $P=100 \%$ ) (Fig. 3). On the other hand, average Y305 showed a discrete decreasing trend as $P$ increased (Fig. 3). Haile-Mariam et al. (2003) reported positive genetic $(0 \cdot 36)$ and environmental $(0 \cdot 16)$ correlations between lactation length and persistency, and almost null genetic $(0 \cdot 0)$ and negative environmental (-0.09) correlations between average daily milk yield and persistency. It is important to say that association among persistency and other traits, as milk yield and lactation length, will depend on the method used to estimate the persistency measure (Jakobsen et al. 2002; Pereira et al. 2012).

The heritabilities for $P$ obtained for the two data sets were identical, with mean values of 0.08 (Table 2), indicating that most part of the phenotypic variation in this trait is due to non-genetic factors and the expected response to selection would therefore be slower. In addition, average repeatability for $P$ was $0 \cdot 21$ (Table 2). Similar estimates have been reported by Cole \& Vanraden (2006) and Cole \& Null (2009) who studied a measure of persistency that was independent of Y305 in different taurine breeds. The authors found a heritability of $0 \cdot 09-0 \cdot 18$ and repeatability of $0 \cdot 18-0 \cdot 28$.

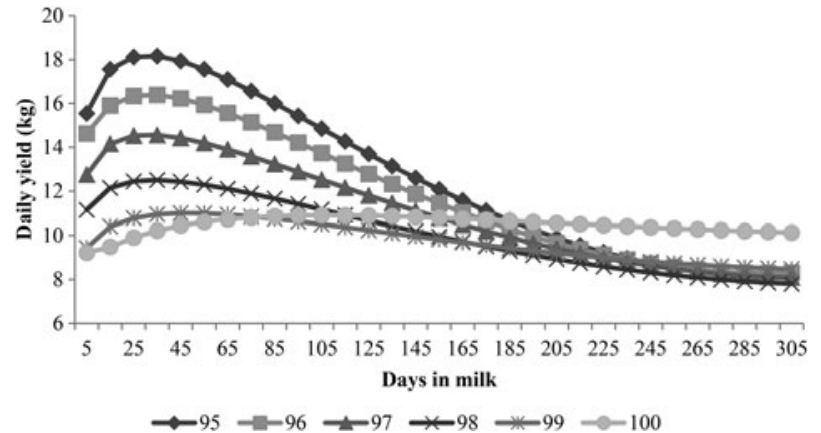

Fig. 2. Mean daily milk yield curves obtained for cows with different levels of milk yield persistency until 305 d (95 to 100\%).

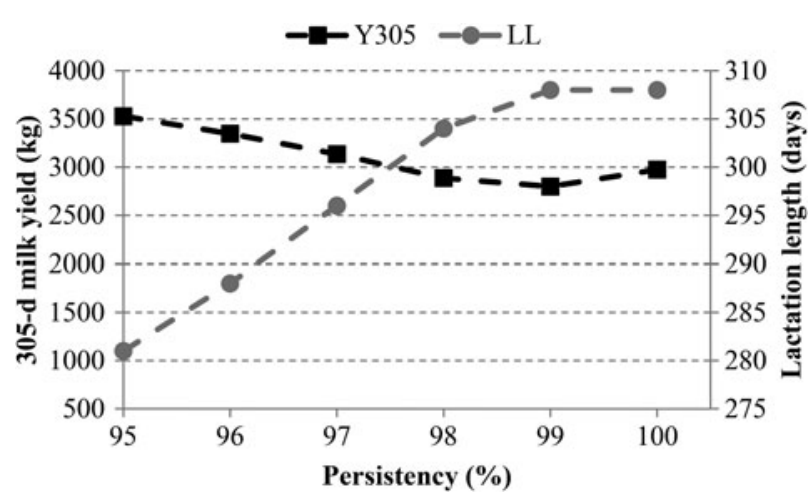

Fig. 3. Mean 305-d cumulative milk yield (Y305) and lactation length (LL) for cows with different levels of milk yield persistency until 305 d (95-100\%).

The heritabilities for $P$ obtained in the present study were generally lower than those reported in the literature for measures of persistency obtained as a function of days in milk using random regression models (Jakobsen et al. 2002, Pereira et al. 2012). According to Cole \& Vanraden (2006), this finding can be explained by the fact that most of these measures of persistency show a moderate to high genetic correlation with milk yield.

The mean phenotypic correlations between $P$ and Y305 (Table 3) were positive for the two data sets, but low as 
Table 2. Posterior means, standard deviation (SD) and 95\% High Density Interval (95HDI) of additive genetic $\left(\sigma_{a}^{2}\right)$, permanent environmental $\left(\sigma_{p e}^{2}\right)$ and residual variance $\left(\sigma_{r}^{2}\right)$, heritability $\left(h^{2}\right)$, and repeatability $(r)$ obtained for milk yield persistency until $305 \mathrm{~d}$

\begin{tabular}{|c|c|c|c|c|c|c|}
\hline & \multicolumn{3}{|l|}{ AN1 } & \multicolumn{3}{|l|}{ AN5 } \\
\hline & Mean & SD & $95 \mathrm{HDI}$ & Mean & SD & $95 \mathrm{HDI}$ \\
\hline$\sigma_{a}^{2}$ & $0 \cdot 17$ & 0.06 & $0 \cdot 06-0 \cdot 30$ & $0 \cdot 22$ & 0.04 & $0 \cdot 14-0 \cdot 30$ \\
\hline$\sigma_{p e}^{2}$ & - & - & - & $0 \cdot 35$ & 0.05 & $0 \cdot 25-0 \cdot 45$ \\
\hline$\sigma_{r}^{2}$ & 1.96 & 0.07 & $1 \cdot 82-2 \cdot 09$ & $2 \cdot 22$ & 0.05 & $2 \cdot 13-2 \cdot 32$ \\
\hline$h^{2}$ & $0 \cdot 08$ & 0.03 & $0 \cdot 03-0 \cdot 14$ & $0 \cdot 08$ & $0 \cdot 01$ & $0 \cdot 05-0 \cdot 11$ \\
\hline$r$ & - & - & - & $0 \cdot 21$ & 0.01 & $0 \cdot 18-0 \cdot 24$ \\
\hline
\end{tabular}

AN1, analysis considering only first-lactation cows; AN5, analysis considering all lactations up to fifth calving.

Table 3. Posterior means, standard deviation (SD) and $95 \%$ High Density Interval (95HDI) of additive genetic $\left(\sigma_{a}\right)$ and phenotypic $\left(\sigma_{p}\right)$ correlations of milk yield persistency until 305 d with lactation length (LL) and 305-d cumulative yield (Y305)

\begin{tabular}{|c|c|c|c|c|c|c|}
\hline & \multicolumn{3}{|l|}{ AN1 } & \multicolumn{3}{|l|}{ AN5 } \\
\hline & Mean & SD & $95 \mathrm{HDI}$ & Mean & SD & $95 \mathrm{HDI}$ \\
\hline \multicolumn{7}{|l|}{ Y305 } \\
\hline$\sigma_{a}$ & $0 \cdot 09$ & $0 \cdot 17$ & -0.25 to 0.41 & $-0 \cdot 14$ & 0.09 & -0.30 to 0.04 \\
\hline$\sigma_{p}$ & $0 \cdot 13$ & $0 \cdot 02$ & $0 \cdot 09-0 \cdot 17$ & $0 \cdot 05$ & $0 \cdot 01$ & $0 \cdot 03-0 \cdot 07$ \\
\hline \multicolumn{7}{|l|}{ LL } \\
\hline$\sigma_{a}$ & $0 \cdot 50$ & $0 \cdot 13$ & $0 \cdot 24-0.73$ & $0 \cdot 27$ & $0 \cdot 10$ & $0 \cdot 08-0 \cdot 47$ \\
\hline$\sigma_{p}$ & $0 \cdot 25$ & $0 \cdot 02$ & $0 \cdot 22-0 \cdot 29$ & $0 \cdot 29$ & $0 \cdot 01$ & $0 \cdot 27-0 \cdot 31$ \\
\hline
\end{tabular}

AN1, analysis considering only first-lactation cows; AN5, analysis considering all lactations up to fifth calving.

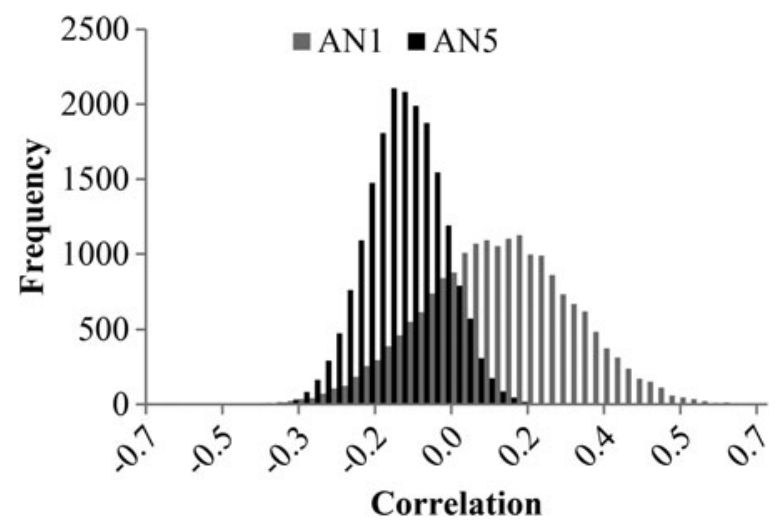

Fig. 4. Marginal posterior distributions of the additive genetic correlation between milk yield persistency and 305-d cumulative yield considering only first-lactation cows (AN1) or all lactations up to fifth calving (AN5).

expected. In contrast, the mean additive genetic correlations differed between the two data sets and were both of low magnitude. Considering only first lactations (AN1), the $95 \%$ High Density Interval ranged from -0.25 to $0 \cdot 41$, including zero within a high probability density area (Fig. 4). For the AN5 data set, the 95\% High Density Interval ranged from -0.30 to 0.04 , including zero but within a region of lower probability density when compared to AN1 (Fig. 4).

The DIC value for MCOV0 was 9.96 units lower than that obtained for MCOV1, providing evidence that the additive genetic covariance between $P$ and Y305 is null. These results indicate that, in fact, the measure of persistency studied is independent of the level of production. Positive and low genetic correlations between measures of persistency and milk yield have been reported in the literature (Cole \& Vanraden, 2006; Cole \& Null, 2009).

The phenotypic correlations between $P$ and LL were $0 \cdot 25$ and 0.29 for AN1 and AN5, respectively, indicating that cows with higher levels of persistency tend to present longer lactations (Table 3). The genetic correlation between $P$ and LL was markedly higher when only first lactations $(0 \cdot 50)$ were considered compared to the analysis that took into account all lactations up to fifth calving $(0 \cdot 27)$. This finding indicates greater synergy between genes that control the two traits during first lactation of the productive life of cows.

The average genetic progress between 1985 and 2006 was $13.83 \mathrm{~kg}$ and $0.45 \mathrm{~d}$ per year $(P<0.0001)$ for $\mathrm{Y} 305$ and $L L$, respectively. On the other hand, the genetic trend for $P$ did not differ significantly from zero $(P>0 \cdot 05)$, indicating that selection for increased milk yield would not increase persistency, as expected since the genetic correlation between these traits was low or zero. A substantial increase in genetic gain for Y305 and LL was observed after 1993, the year when the first result of progeny testing of the breed was published. The genetic progress for Y305 and LL was $27 \cdot 22 \mathrm{~kg}$ and $1.12 \mathrm{~d}$ per year, a consequence of the more intensive use of proven bulls. Again, the genetic trend for $P$ was zero $(P>0 \cdot 57)$. According to Pereira et al. (2011), the effect of pregnancy needs to be 
included in models used for the genetic evaluation of dairy cattle since the absence of this effect results in the overestimation of breeding values for milk yield persistency in nonpregnant cows. Prior adjustment of persistency records for this effect may provide heritability estimates higher than those obtained in the present study.

Simultaneous selection for persistency and milk yield in herds raised in tropical regions should increase milk yield without the need to increase peak yield, which is limited by the nutritional characteristics of tropical pastures. However, studies should be conducted to estimate the economic weights of each trait in a selection index.

With this results, we could conclude that milk yield persistency as measured in this study has low heritability; milk yield persistency and lactation length are moderately correlated genetically and selection for persistency can increase lactation length; the measure of milk yield persistency studied here is genetically independent of total milk yield and could be included in routine genetic evaluations of dairy cattle.

\section{References}

Ali TE \& Schaeffer LR 1987 Accounting for covariances among test day milk yields in dairy cows. Canadian Journal of Animal Science $\mathbf{6 7}$ 637-644

Appuhamy JADRN, Cassell BG, Dechow CD \& Cole JB 2007 Phenotypic relationships of common health disorders in dairy cows to lactation persistency estimated from daily milk weights. Journal of Dairy Science $\mathbf{9 0}$ 4424-4434

Appuhamy JADRN, Cassell BG \& Cole JB 2009 Phenotypic and genetic relationships of common health disorders with milk and fat yield persistencies from producer-recorded health data and test day yields. Journal of Dairy Science 92 1785-1795

Butler WR 2000 Nutritional interactions with reproductive performance in dairy cattle. Animal Reproduction Science 60-61 449-457

Cole JB \& Vanraden PM 2006 Genetic evaluation and best prediction of lactation persistency. Journal of Dairy Science 89 2722-2728

Cole JB \& Null DJ 2009 Genetic evaluation of lactation persistency for five breeds of dairy cattle. Journal of Dairy Science 92 2248-2258

Haile-Mariam M, Bowman PJ \& Goddard ME 2003 Genetic and environmental relationship among calving interval, survival, persistency of milk yield and somatic cell count in dairy cattle. Livestock Prodution Science 80 189-200
Harder B, Bennewitz J, Hinrichs D \& Kalm E 2006 Genetic parameters for health traits and their relationship to different persistency traits in German Holstein dairy cattle. Journal of Dairy Science 89 3202-3212

Hickson RE, Lopez-Villalobos N, Dalley DE, Clark DA \& Holmes CW 2006 Yields and persistency of lactation in Friesian and Jersey cows milked once daily. Journal of Dairy Science 89 2017-2024

Jakobsen JH, Madsen P, Jensen J, Pedersen J, Christensen LG \& Sorensen DA 2002 Genetic parameters for milk production and persistency for Danish Holstein estimated in random regression models using REML. Journal of Dairy Science 85 1607-1616

Jakobsen JH, Rekaya R, Jensen J, Sorensen DA, Madsen P, Gianola D, Christensen LG \& Pedersen J 2003 Bayesian estimates of covariance components between lactation curve parameters and disease liability in Danish Holstein cows. Journal of Dairy Science 86 3000-3007

Kamidi RE 2005 A parametric measure of lactation persistency in dairy cattle. Livestock Production Science 96 141-148

Lang SLC, Iverson SJ \& Bowen WD 2012 Primiparous and multiparous females differ in mammary gland alveolar development: implications for milk production. Journal of Experimental Biology 215 2904-2911

Misztal I 2011 BLUPF90 Manual. http://nce.ads.uga.edu/ ignacy/new programs.html Accessed on 12/09/2011

Muir BL, Fatehi J \& Schaeffer LR 2004 Genetic relationships between persistency and reproductive performance in first-lactation Canadian Holstein. Journal of Dairy Science 87 3029-3037

Pereira RJ, Santana JRML, Bignardi AB, Verneque RS, El Faro L \& Albuquerque LG 2011 Effect of pregnancy on the genetic evaluation of dairy cattle. Genetics and Molecular Research 10 2190-2201

Pereira RJ, Verneque RS, Lopes PS, Santana ML, Jr, Lagrotta MR, Torres RA, Vercesi Filho AE \& Machado MA 2012 Milk yield persistency in Brazilian Gyr cattle based on a random regression model. Genetics and Molecular Research 11 1599-1609

Pereira RJ, Bignardi AB, El Faro L, Verneque RS, Vercesi Filho AE \& Albuquerque LG 2013 Random regression models using Legendre polynomials or linear Splines for test-day milk yield of Dairy Gyr (Bos indicus) cattle. Journal of Dairy Science $\mathbf{9 6} 565-574$

Santos FAP, Martinez JC, Greco LF, Carareto R \& Penati MA 2007 Supplementation of grazing cows: technical and economic considerations seeking greater profitability. In The Brazil and the New Era of the Milk Market - Understanding to Compete, 1st edition. pp. 249-300 (eds MP Carvalho, MV Santos (Org.)). Uberlância, MG: Impressão Gráfica Rio Pedrense

Smith BJ 2007 boa: an R Package for MCMC Output Convergence Assessment and Posterior Inference. Journal of Statistical Software 21 $1-37$

Spiegelhalter DJ, Best NG, Carlin BP \& Van Der Linde A 2002 Bayesian measures of model complexity and fit. Journal of the Royal Statistical Society: Series B (Statistical Methodology) 64 583-639

Togashi K \& Lin CY 2004 Efficiency of different selection criteria for persistency and lactation milk yield. Journal of Dairy Science 87 1528-1535 